\title{
EL INTELECTO EN GUILLERMO DE OCKHAM
}

\author{
Francesç Fortuny \\ Universitat de Barcelona
}

\begin{abstract}
RESUMEN
La doctrina ontológica sobre los dos intelectos aristotélicos, creada en el siglo XIII, acaba su andadura definitivamente con la epistemología de Ockham. La epistemología realístico-proposicionalista de Ockham reduce el intelecto a una connotación: intelecto denota el alma o, mejor, el sujeto pensante todo y uno; pero connota la función cognoscitiva del hombre. El hombre es esencialmente libre y dirige el conocer hacia su objeto, es vida y actividad; pero la función cognoscitiva denotada es pasiva.
\end{abstract}

Palabras clave: Intelecto, connotación, epistemología, discurso, función

\begin{abstract}
The ontological theory about the two aristotelical intellects, created in the 13th century, finishes finally its itinerary with Ockham's epistemological theory. The realistic-propositionalist Ockham's epistemological theory reduces the intellect to a connotation: intellect denotes the soul, or better, the thinking subject whole and one; but connotes the man's cognitival function. The man is essentially free and directs his knowledge to its object, it is life and activity; but the denoted acognitival function is passive.
\end{abstract}

Key words: Intellect, connotative, epistemology, discourse, function

\section{UNA LARGA HISTORIA PRECEDENTE: EL «NOUS-LOGOS» ARISTOTÉLICO}

Cuando el tema del intelecto llega a Guillermo de Ockham (h.1285-h.1348) ha recorrido largo trecho. Nació para una terminología técnica filosófica de la cabeza de Aristóteles, no sin aparecer implicado Platón en el tema.

Con el Estagirita ya nace dividido en intelecto agente e intelecto paciente. Pero es el único verdadero intelecto, el Nous cósmico, lo que se divide en sí mismo en activo y pasivo; sólo remota y participativamente, esta partición puede «decirse» del intelecto humano y, siempre, en el bien entendido que tanto en el pequeño intelecto humano como en el gran Nous cósmico, agente y paciente se inscriben en un paradigma discursivo «biológico» y, mejor aún, «fisiológico». En la unidad óntica de un proceso vital, una parte se puede decir que hace una cosa y la otra que es hecha tal cosa: en realidad se trata de dos momentos de una idéntica entidad autodinámica y autoconstructiva que va creciendo, dándose un pleroma.

Luego el Nous-Logos, en idéntico paradigma fisiológico, quedó arropado más explícitamente, de una parte, por el Uno, de la otra, por la Vida o el Alma cósmica; en medio el Logos único del Uno. Son las grandes hipóstasis del neoplatonismo, en realidad tres modalidades inmanentes de la única vida inteligente. Es el típico tres en uno del aristotélico «noésis noése$o s$, zooé». Triple que en Plotino más bien se ordenaba conceptualmente y, por ende, en una 
forma aparente descendente, incluso en la inmanencia de la unidad dinámica primera. En cambio, en Proclo se mantenía la terna explícitamente en el mismo plano, para descender en tres líneas paralelas, por la escala de la línea entitativa, de la noética y de la vital, en discursos de alcance diferente y de opuesto contenido.

En la forma neoplatónica, el tema del intelecto cósmico entra en la tradición islámica, y permanece poco cambiado en la filosofía clásica musulmana y hebrea, con los dos grandes cordobeses, Averroes y Maimónides. Son dos líneas filosófico teológicas que tienen su paralelo cristiano en el arrianismo y el monofisismo posterior.

\section{DESPUÉS DEL AÑO MIL, LA EUROPA LATINA ES DIFERENTE}

Pero en la Europa Latina, tierra que está sufriendo una profunda transformación social después del nemotécnico Año Mil, el intelecto - Nous y Lógos clásicos-vira hacia una profunda mutación. Simplemente deja de ser un intelecto cósmico. Como tal nous cósmico ni tan sólo perdura en Dios, desvanecido por la ampliación incontenible de la platónico-neoplatónica «inefabilidad» del Bien y el Uno, y por la «imposibilidad» de la cuarta species de la Physis del Eriúgena, que con ella pone fundamento y epílogo a su teología negativa. Luego se suma el triunfo de la «sobrenaturalidad» estricta, que exigen los nuevos teólogos escolásticos desde mediados del s. XIII. Y el intelecto pasa a ser única y exclusivamente una capacidad, facultad, función o resultado de la acción de la persona humana en su realidad superior.

La desneoplatonización intelectual de la Europa Latina, plenamente triunfante en el siglo XII, da muy pronto en una proliferación de entidades, que incluso alcanzan a ser calificadas de substantivas en más casos de los que sería menester. Aun sin recibir este reconocimiento substantivante, si que se erigen tales entidades con un entorno de discursos que las tratan como substancias, sin afirmar tal substantividad; o hablan de ellas a semejanza de discursos que implican una substantividad indiscutible, sin reconocer tal implicación, y aun negándola. Rota la flexible, pero férrea, unicidad del cosmos neoplatónico, surge la proliferación y la multitud de substantividades por todas partes.

El intelecto, bajado del Cosmos eterno para anidar en nuestro mundo efímero, en la cabeza del hombre, pero inmerso en este contexto de proliferación substantivista, se resiste a perder viejas preeminencias, cuando ya tanto ve recortado su poder. De ser señor y ordenador del Cosmos, el intelecto pasa a ser capacidad noética frente a la realidad, una realidad caída también, con él, en la pulverización multitudinaria y el caos. Y el intelecto casi llegará a ser una realidad substantiva, casi da realidad al mítico viejo auriga platónico, lo inmortal, conductor de la cartesiana substancia extensa mortal, y un si es no es mecanicistas ella y su conductor. Jamás Platón pudo soñar en esto, Descartes sí, ubicado ya en la segunda etapa de la «Modernidad» y en su rama más radical y equívoca como filósofo de la ciencia.

\section{FRUTO DE UN TIEMPO DE MUTACIÓN Y TRÁNSITO, PRONTO SE DESVANECE EL INTELECTO CASI SUBSTANTIVO}

El aparente triunfo de un intelecto humano que deviene casi substantivo, es tan efímero como todo el circunstancial remolino de conceptos fluctuantes que buscan nuevo significado. Es la vorágine que transforma el único discurso sobre el Cosmos viviente del griego clásico, helenista y patrístico, en un discurso plural y analítico, «científico», sobre un universo de cosas autónomas, entre el s. X y el XIII. Vida, inmortalidad, facultad, forma, materia y tantos otros; todos van perdiendo su significación aristotélica, la que tenían en un paradigma unitario fisiológicamente. Pese a la constante «recuperación» - se dice- del Estagirita, todos cada vez están más centrados en una naturaleza multitudinaria cuya pluralidad salta a la vista y nunca 
fue aristotélica, y a la que cuenta y calcula la razón matemática, o divide y une la lógica, sin hallar ni reposar nunca en una unidad total y, menos aún, una realidad viva total.

En este ambiente de efímera transformación entre el mundo «antiguo» clásico y el mundo «moderno», desaparece la vieja oposición aristotélica entre una parte dinámica de la vida, que hace brotar la pluralidad en el continuum infinitum de la inteligencia una, la otra parte, y que es inteligencia detallada y plural de la vida inteligente del Uno continuo del arché; y esta dualidad - además - ya es el brotar del fecundo dinamismo de la Vida única, radical y ordenada. El discurso, siempre único e inmanente al único uno animado intelectual existente, deviene ahora, en los ss. XII-XIII, oposición incluso «real» entre «realidades» variopintas.

Aparece en este intersticio el intelecto agente, un eficiente obrero, productor, que, aplicado a su trabajo, «ilumina» los productos de la sensibilidad presentes en la imaginación, y hace «saltar», más que «manifestarse», a la «forma» — una, simple, intelectual y eterna - que cae -abstracta, ilimitada y universal- en el receptivo y plástico intelecto paciente, ni afectado ni afectante por la cantidad, accidente impropio para un intelecto simple y para una idea simple.

El intelecto que era la totalidad viva de Aristóteles, y su inmanente dualidad de agente y paciente, han entrado a formar parte de una ontología, casi una física, del conocimiento en los sujetos inteligentes. Se da la explicación del origen del producto mental denominado «concepto», fruto de la fecundación del intelecto paciente por la semilla de la forma eterna que está en el ente real, liberada por el trabajo obrero del intelecto agente, mucho más que no una epistemología del conocer. Estamos en siglos de nacimiento del gran mercado y de la organización de la sociedad en vistas a él, olvidando viejos parámetros tribales, familiares, feudales o propios de una «physis» (lo que ha de nacer). Son años de búsqueda y triunfo de la hegemónica causa eficiente, de olvido de la final porque todavía dependen de la naturaleza en alto grado y ésta funciona sola. Lo que era dinamismo vital y vida en la misma inmanencia del viviente, se torna ahora eficiencia y producto receptivos de lo «otro» en la pluralidad.

A Ockham le alcanza esta versión un tanto grosera del conceptus mentis y, no sin humor, apunta que tampoco hay ninguna necesidad de interpretar tan al pie de la letra una metáfora de concepción biológica en la cuestión del origen del conocimiento (I Sent. Q.).

\section{MÁS ALLÁ DE FÍSICAS Y DE METAFÍSICAS DEL CONOCIMIENTO}

En efecto, a Ockham ya no le alcanzan los devaneos primeros del conceptualismo griego, después de la «física noética y subjetiva» del conocimiento del Eriúgena (s. IX) en su deslumbrante Periphyseon, todavía bien vivo e influyente en el s. XII. Ockham ya no entiende las substantivaciones, no entiende ni le preocupa la finalidad de las «ontologías del conocimiento» del s. XIII, que en los epígonos alcanzan incluso a reducir el acto de conocer a un «conceptus literaliter sumptus».

Ockham no siente la necesidad de explicar el «ser» del conocimiento o de la inteligencia, en verdad bien poco «visible», como bien poco visible es cualquier substancia en sí misma, y sólo aparente a través de los accidentes, como todos reconocen y bien pocos aplican. Lo que le preocupa al buen franciscano inglés es acotar la potencia y los límites de cada discurso en el que, evidentemente, el conocimiento existe y se muestra útil, fidedigno y verificable.

Para Ockham ya no existe el problema del conocimiento cierto y verdadero de la realidad en sí; a la realidad en sí ya no la alcanza la epistemología de Ockham, ni la echa de menos. Conocemos la realidad sólo a través de los discursos mentales, primariamente; o los verbales o los escritos, secundariamente. $Y$ por esta vía de la aquilatación de los discursos varios, Ockham salta por encima de las sustantivaciones del s. XII y XIII para enlazar de un modo bien nuevo con las preocupaciones reales del Aristóteles histórico, por la unificación de los discursos contradictorios. Pero esta vez desde la subjetividad y no desde la Physis. 
Ockham no cree que el hombre «corpulentus» haya de «recordar» una preexistencia noética -muy comprensible en la Physis de la Grecia clásica, imposible en el creacionismo cristiano-, ni esperar una iluminación natural por la presencia y coadiubación del Creador en cada acto humano —opción epistemológica agustiniana, débil sin el monismo cosmológico, que era consecuente con el arché, pero «pagano»-. Ockham no cree que los conceptos sean unas «ideas» que vienen de una superioridad —el Nous cósmico o el Dios creador-.

$\mathrm{Ni}$ tampoco apuesta Ockham por una verdadera «abstracción», operación que separaría el conocimiento intelectual frente al sensible como acciones correspondientes a dos opuestas substantividades, por mucho que sean camufladas de meros principios de ser en una ficción «meta-física». Frente a la abstracción de la teoría del siglo anterior, Ockham simplemente no tiene nada de dónde abstraer, ni qué abstraer: la substancia está simplemente oculta y la esencia es una definición mental y sólo mental en un discurso.

Para Ockham, la única «abstracción» es no tener ya la intuición inmediata, a la vez sensible e intelectual, del denotado del sujeto y del predicado de una frase, y no poder, entonces y por evidencia inmediata, juzgar verdadera o falsa una proposición de existencia.

Ockham, por otra parte, no cree que los universales sean de tal naturaleza sublime que su poder no pueda proceder de la humilde combinación subjetiva del dato empírico inmediato con ciertos formalismos lógicos, los cuales generan proposiciones y discursos a partir de la vivencia puntual de intuiciones inmediatas de aspectos parcialísimos de las cosas. La universalidad, en la doctrina de Ockham, es y sólo es una cuantificación lógica en el discurso; es un determinado uso de términos o signos que siempre denotan singulares, pero pueden hacerlo de formas diferenciadas en una amplia «gramática» que incluya también unas formalidades lógicas.

\section{INTELIGIR Y COMPRENDER LO VIEJO Y LO NUEVO: ACEPTAR POR COHERENCIA SIN BUSCAR CON AFÁN}

Digamos ya de una vez, que todas estas notas características del pensamiento de Ockham no son precisamente una novedad por sí mismas; más bien representan un retroceso y una recuperación, pero de cariz muy peculiar.

En general la escuela franciscana medieval no ama las novedades, sino que desde lo más tradicional genera novedades al pensar personalmente la realidad nueva del entorno. Como dirán más tarde, en el siglo XVI, del nominalismo derivado de Ockham, la franciscana es una escuela tradicional non affectata, libre, libre incluso del prurito de estar al día, de ser sabia. Intèntemos focalizar el origen de su tradicionalismo innovador con cierta exactitud; nada más ilustrativo que una buena localización histórica del pensamiento de un gran autor, y nuestro franciscano inglés ciertamente es un gran escritor filosófico.

En efecto, Ockham, en verdad es muy tradicional y muy agustiniano, como buen franciscano. Sin pretensiones doctorales, los franciscanos no aspiran a apabullar con su sabiduría o dictar la ortodoxia con su poder a los nuevos miembros de la inteligenzia mercantil, los peritii universitarios. No quieren hablar su lenguaje; no necesitan adoptar con urgencia los novedosos conceptos aristotélicos de Artes y sus derivados, los averroístas latinos o los juristas; los conocen, los usan libremente si es el caso.

Los franciscanos son modestos testigos de la fe teológica de siempre, que buscan conocer bien y explicar claro y sencillo; no necesitan ser grandes sabios, sino portavoces tradicionales del Dios viviente de siempre y del pueblo, y no del Dios científico y polémico de los magistri académicos del momento; eso sí, necesitan hacerlo con dominio de su fe y de los instrumentos para transmitirla a y en su sociedad.

$\mathrm{Y}$, así, los franciscanos medievales se convierten en grandes descubridores y portavoces de las verdades de su época, pero con temas y textos «de siempre» que ellos enriquecen y restauran: ellos inteligen y comprenden lo viejo y lo nuevo, y lo comunican con retórica certera 
a sus oyentes. Si hay novedad en su pensamiento es por la desbordante creatividad y vitalidad de la época, del entorno, no porque la busquen ni deseen en el reducto especializado de la universidad y desde este punto de vista. Lógicamente, esta novedad franciscana vendrá espléndidamente sazonada en rico contexto de tradición y cultura, precisamente porque no es buscada, sino ya poseída, encontrada casi a desagrado y admitida por bien viva y significativa, sin rechazarla a priori por antigua o normal o cotidiana y simple.

\section{UN PENSAMIENTO DE CARIZ AGUSTINIANO, PERO DE LECTURA ERIUGENIANA}

La tradición agustiniana de Ockham es muy clara: el conocimiento ciertísimo es el que el hombre tiene inmediatamente, sin sentidos, sin raciocinios; es el conocimiento de «sum, nosco, amo», «soy, conozco, amo» y, en estas verdades, no hay posibilidad ninguna de error, decía Agustín de Hipona (esp. en Ciudad de Dios, XI, 24, con muchos paralelos).

Ockham acepta que, en efecto, este triple conocer agustiniano es un conocimiento perfecto, paradigma y modelo de todo conocimiento humano. Su modelo ideal de conocimiento es inmanente al sujeto, sin mediaciones, como destacó el Padre de la Iglesia nueve siglos antes. Pero Ockham no lo valora exactamente en la literalidad agustiniana. El franciscano no ignora los autores que median entre él y el obispo de Hipona. Es poco probable que lo leyera directamente, pero el pacífico - y exitoso- impacto durante cuatro siglos del Eriúgena en el pensamiento latino ni se ha olvidado ni fue baladí. En el sum, nosco, amo, después del Eriúgena, vuelve a resonar, puro y sin psicologismos, el viejo arché platónico-aristotélico, convertido en poderosa vida inteligente única que se realiza en su pleroma «físico», múltiple en la categorización discursiva; la intelección de una inteleligencia que ya es vida en sólo esta unidad triple, y que, en decirse, crea y se crea a sí misma en una estupenda unidad de lo múltiple en la vida única del Uno y del Todo. Donde Agustín veía sólo una verdad categorial ciertísima, Ockham lee el paradigma perfecto del conocer inmanente del hombre que le es vida intelectiva única, subjetividad óntica.

En la universidad de Oxford, libre intelectualmente desde su fundación como jamás lo fue la parisina, todo confluye y se armoniza, más que condena: Aristóteles, Averroes, Agustín, el De Causis y los comentarios del Eriúgena al Pseudo Dionisio, si no su mismo Periphyseon o la abreviatio de él elaborada por Honorius Augustudunensis (m. 1152). La poderosa subjetividad divina, clara y magistralmente dibujada por el irlandés carolingio, fecunda las páginas del Inceptor franciscano.

Pero el paradigma de la subjetividad ya no sobrevuela en Oxford y Londres por la esfera divina como en la obra del maestro carolingio, sino que la subjetividad ockhamista es la del espíritu humano y sólo la suyạ. La frase de Agustín, sintetiza la bajada hasta una subjetividad a talla humana sólo sugerida como ejemplo pedagógico proporcionas en Juan Escoto Eriúgena. Además, la subjetividad de Ockham (I Sent. Prologus, q. Ia , a. 1, Corollarium II) no es ya la psicologista del obispo de Africa. La poderosa estructura noética que permite a Ockham afirmar (I Sent. Prologus, q. İ, a. 1, conclusio tertia) que nada exterior a la mente es causa próxima del conocimiento, ni aún del conocimiento sensible, es la subjetividad creadora del carolingio. Desarrollamos extensamente el tema de la subjetividad del conocimiento de Ockham en La Ontología del espiritu: principio de la epistemología de G.Ockham. en la revista de la Facultad de Filosofía «Convivium» (Barcelona, 1990).

La filosofía del franciscano es tan seria y vigorosa como la clásica griega. No habla de imaginaciones, emociones y ensoñaciones que el hombre finito pueda categorizar y hacer suyas; habla Ockham de la generación de un todo único subjetivo, como los griegos hablaban de la realidad del cosmos único extramental de la Physis, en, del y para el cual vivían y pensaban. Si en Aristóteles el ser se dividía radicalísimamente en ens a se y ens ab alio y a se era el arché 
de la Physis extramental en la que vivía, ahora en Ockham ya el a se es la subjetividad inteligente, y ens ab alio, real pero accidental y mutable, la totalidad de sus discursos en los que se dice y torna consciente como «yo en el mundo» unitario y guía sus pasos con precisión y eficacia. Todo pensar es pragmático en la subjetividad de Ockham, como lo es la generación de la Physis y la reflexión del hombre en ella para Aristóteles.

Estamos ya con Ockham en el camino que conduce a la Substancia de Spinoza, con sus dos atributos de inteligencia y extensión, frente a las substancias pensantes y extensas cartesianas o del s. XIII medio. Hay una senda real, sobre la base de la subjetividad divino-humana, entre el neoplatonismo pleno del Eriúgena y la Modernidad plena de Spinoza y Leibniz, y el hito central es Ockham, Petrus Ramus y Nicolás de Kues. Ockham iniciando con base seria la formalidad de la lógica, los dos últimos ya en la esfera de la matemática.

\section{ANTIPSICOLOGISMO DE OCKHAM HASTA EL ERROR}

Ockham no se pierde en una psicologística y categorial presencia del acto de ser intelectual a sí mismo, como implica la frase y el contexto del Padre de la Iglesia. El medieval inglés incluso se excede en su celo por ahorrar cualquier equívoco psicológico. El gran error de su vida fue, precisamente, efecto de ese exceso de celo en excluir toda consideración psicologística donde sólo debía brillar la epistemología.

El gran error de Ockham se halla en el Prólogo a la Expositio l. Physicorum, en donde acentúa «No tu punto de vista o el mío, sino la recta suppositio de los términos en la proposición es quien determina la verdad o falsedad». Ockham objetiva al máximo la ciencia en la materialidad significativa de la proposición frente a los psicologismos pseudosubjetivos. Pero con ello ayuda al olvido de la misma subjetividad que produce la objetividad del conocimiento y consigue oscurecer la creatividad de la persona humana en su «hacer ciencia», por objetiva que ésta sea, y crea para los posteriores la posibilidad lingüística que más temía Platón: cambiar la experiencia vivida por la fórmula recepta escrita. Ockham, con su exceso, prenuncia el principio del fin de la misma Modernidad que crea. La buena fórmula arrancaba de la negatividad eriugeniana, pero Ockham - como el Eriúgena - no poseía ni la curiosidad ni los medios para desarrollarla, sólo conscientes después de Hegel.

Siempre y únicamente, Ockham habla del discurso (argumentum), de sus elementos y de sus condiciones de posibilidad. Así comienza, se desarrolla y concluye la Lógica Maior del Inceptor. Y, como si aplicara, sin perder de nuevo el tiempo en explicar el motivo, la fecunda negatividad radical del irlandés de cuatro siglos antes, nunca habla directamente de la «substancia pensante», de su ser o de sus condiciones de acción, de sus productos, los conceptos en su entidad objetiva. Ockham no conoce conceptos salvo como simples signos, que son algo así como vivencia y cualidad habitual, pero nunca conocimiento complejo y totalidad cerrada y excluyente, con visos de eternidad. Conocimiento sólo lo hay en el discurso cuya mínima expresión es la frase, signo complejo, y propiamente el discurso hasta cierto punto, momentáneamente, cerrado sí y sólo sí resulta eficaz, por bien determinado, simple y coherente.

\section{LA SUBSTANCIA INTELIGENTE, COMO TODA SUBSTANCIA, ES SÓLO COGNOSCIBLE EN Y POR SUS ACCIDENTES}

Quien sabe que la subjetividad — como toda substancia en el sentido más vivo y clásicoes y sólo es un «no» a cualquier categoría, se limitará a conocerla a través de sus manifestaciones, y a aplicarle una especie de matizada «teología» negativo-positiva como la de los «hyper-» y la creación del Eriúgena. 
Ockham sólo analiza los discursos en los que se muestra la inteligencia; jamás afronta la esencia y naturaleza del intelecto en sí mismo o del propio conocimiento en sí mismo. Él no ofrece una «física del intelecto» o una «génesis ontológica de los conceptos». Ockham anali$\mathrm{za}$ las condiciones del discurso verdadero en las que se muestra la actuación de la inteligencia y los rasgos de su producto, el discurso cognoscitivo. Pero, si en Aristóteles el conocimiento de la realidad es la Física, con el «sexto libro de la Física» incluido, el De Anima, y acompañan y explicitan sus condiciones inmanentes la Filosofia Primera y el Organon, en Ockham no es así. En el Inceptor no se plantean las dos explicitaciones: ni la del arché ni la del discurso en sus condiciones y herramientas «lógicas», ni naturales ni formales. Mucho menos alcanzará postular un «yo trascendental» como Kant. Ockham da las condiciones fenoménicas del discurso auténtico, y la descripción y valoración epistemológica de las acciones del conocer y su sujeto, en la Lógica, en el Prologo a la Expositio de la Física, o de los comentarios a los libros de las Sentencias, y el contenido de su labor cognoscitiva en todas partes y al mismo tiempo. Nunca Ockham da libre curso al «tratado» fáctico sin presencializar en él al sujeto responsable del pensamiento expuesto.

Pese a algunos precedentes manualescos y a la especialización de las facultades, Ockham todavía no se ha «manualizado» a sí mismo en su saber, ni deja de ser un filósofo, el especialista en la epistemología de la globalidad unitaria del conocer humano. Los tratados «científicos», las «ciencias» son distinguibles y separables en él sólo fácticamente, por comodidad y utilidad, pero no en su origen vivo, ni en el conocer interior del sujeto.

Todo esto históricamente es posterior, y culmina en la racionalista reforma universitaria de Napoleón, que la estructura sobre nuestra conocida pauta de horarios y manuales. Con el resultado, ni buscado por el reformador ni sensato, de «vivenciar», por enrarecimiento epistemológico, el filosofema de unas «ciencias» que van naciendo y recortando un contenido que antes era del saber filosófico, con toda su pretenciosa mezcolanza de errores y vaguedades. Las ciencias, serias e inmisericordes, chupan la vida y destituyen de valor a la filosofía cuyo poco contenido aprovechable han salvado y afinado ellas.

Sin embargo, no sólo las cosas no son así, sino que, como más sean y más «necesarias» las ciencias de la «tecnociencia», más necesaria harán a la Filosofía. Cuantas más sean, menos manejables por el hombre en su provecho y en el de su sociedad. Más necesitarán una unificación en la vida una, sea como epistemología previa, sea como base unificadora para la inteligencia, sea como valoración frente a persona y sociedad de las posibilidades de las tecnociencias. La pluralidad, en sí, no posee el canon de su eticidad.

\section{RESPUESTAS A LOS ADVERSARII Y RECHAZO DE LOS PROTERVII}

Salvo derivadamente y por exigencia de comprensión de las doctrinas de los adversarii académicos y de respuesta a los protervii, Ockham no proyecta sus reflexiones sobre las categorías aristotélicas, que son la koiné de la intelligenzia de su tiempo. Pero su epistemología de fondo dice qué valoración le merecen estos discursos: son discursos, no realidades; son productos inmanentes de la inteligencia, no cosas en sí presentes en la mente como un todo y vertidas en palabras extrínsecas de un discurso sensible, no sólo en signos diferentes de la cosa, pese a su realismo vivencial en Ockham, sino incluso deficientes, equívocos para la comunicación.

En realidad el discurso de segundo nivel de cariz epistemológico o antropológico de Ockham, es únicamente una parte del discurso físico, del conocimiento inmediato y directo; es la parte que acota y valora las operaciones noéticas directas; son conocimientos concomitantes que valen en tanto que demarcación del discurso directo, sin que haya discurso directo sobre sus implícitos ni ellas sean a su vez discurso directo de algo, sino sólo concomitante. Son discursos extrínsecos sobre las substancias noéticas, las subjetividades, pero constituyentes y axio- 
lógicos $\mathrm{y}$, como tales, aún inmanentes al discurso directo sobre las cosas pese a su radical diferencia: sólo existe un discurso, no mil metalenguajes, en el Venerabilis Inceptor.

Precisamente por esta su austera resistencia a reificar, a cosificar la inteligencia, la subjetividad, el sujeto cognoscente, como si fueran unos vulgares objetos materiales en un lenguaje corpulentus (Pedro Abelardo), Ockham se desliza hacia su error mayor: eliminar la presencia de la subjetividad noética en la génesis de los discursos, confundiendola con la subjetividad psicológica de quienes hablaban como sí las categorías aristotélicas fueran la realidad, cosa que nunca aconteció a su inventor ni a su seguidor inglés.

\section{LA NEGATIVIDAD DE LA SUBJETIVIDAD HEREDADA DEL ERIÚGENA}

No otra cosa que Ockham hizo el Eriúgena en su Periphyseon: conocer a Dios por la vía causal-creatural de los conceptos precedidos de «hyper-», a través de las theofaníai que, absolutamente, no son Dios, pero en las que el propio Dios «se-dice» y, en «decir-se», «se-crea» hasta ser conscientemente y en la negatividad total, una substancia primera perfecta bajo la modalidad inteligente de la negación.

Hubiera leído o no al Eriúgena, Ockham tiene el inmenso mérito de recoger la perfecta subjetividad divina del carolingio y haberla encarnado con pulcritud en los hombres. Recoge el misterio del Dios-acción-inteligente del Eriúgena, para traspasar tal misterio al noumenon del sujeto humano y al noumenon de las cosas vistas por el hombre. $Y$, hasta tal punto sigue al irlandés genial, que también él, Ockham, no ve la realidad si no es en el lenguaje y el discurso, sin inútiles - por imposibles- apelaciones ni a la realidad en sí, ni al sujeto en sí, ni al Dios iluminador.

Ninguna de las tres cosas — realidad, subjetividad, Dios, a la manera ockhamista - las hubiera podido formular Agustín desde su psicologismo. Con su psicologismo, Agustín puede categorizar y dar por buena la categorización. Pero no puede psicológicamente negarla, porqué el psicologismo radica precisamente en aceptar una categorización. Y ello acontece al Padre de la Iglesia, pese a todas las protestas de respeto a la distancia entre Dios y los hombres, protestas extrínsecas al discurso, y desmentidas por zonas ireflexionadas del propio discurso. Agustín será excelente en muchas cosa, pero no ès un autor con pensar sistemático bien cerrado y coherente. Y mucho menos un pensador de la negatividad esencial de la inteligencia. Él contrapone y discute «ideas» platónicas, jamás las niega como tal «idea».

\section{INTELLECTUS AGENT ET PATIENS: OPOSICIÓN PREVIA, DENOTACIÓN Y CONNOTACIÓN DEL INTELECTO}

Llegados a este punto en la descripción de un panorama total y unitario en el que se inscribe Ockham, estamos en situación de comprender qué puede pensar y qué escribirá Ockham acerca del tema del intelecto agente y paciente. Simplemente Ockham no cree en la existencia real de «facultades» y no dirá nada más de lo que se requiera para dar cuenta de sus razones a quienes utilizan estos nombres y conceptos sobre el intelecto. Y, aún con mayor necesidad, si ellos creen que son genuina doctrina del Estagirita. Sus frases sobre el filosofema del intelecto resultan especialmente negativos y breves en el conjunto doctrinal del Inceptor: no son ni tan solo importantes estos conceptos.

Pero una oposición que destaca en su discurso sobre el intelecto, si que es muy reveladora del mundo cognoscitivo por donde se mueve Ockham y de su epistemología: la oposición que establece funcionalmente entre espíritu o alma e intelecto. El espíritu siempre es activo; el intelecto sólo y siempre es pasivo, asegura nuestro pensador. $Y$ subrayamos que se trata de una radical y contradictoria oposición funcional. En realidad vida, espíritu, inteligencia, cuer- 
po y sentidos, en Ockham son una única realidad en la que confluyen diversos discursos, según aspectos realmente inseparables de la misma entidad.

$\mathrm{Si}$ algún principio axiomático está claro para el buen medieval es que ens et unum convertuntur; decir ente, sin duda alguna ni matiz debilitador, implica unidad inviolable, como implica bondad, verdad, alicuidad, cosidad,..., los llamados conceptos trascendentales por la Escolástica. El hombre -y toda unidad substancial de la naturaleza- es una unidad sin paliativos, infraccionable en la realidad por muchos discursos mentales opuestos que genere. Precisamente desde siglos atrás, desde Boecio para los medievales, la dialéctica es el arte de unir lo separado y de separar lo unido, gracias a la inteligencia. La perfecta unidad entitativa del denotado de los conceptos alma, espíritu, intelecto, voluntad, sentidos arranca del axioma ens et unum convertuntur.

Desde el axioma de base para toda entidad, más reforzado si cabe en Ockham que en sus antecesores por una de las varias funciones del «principio de economía», espíritu o alma e intelecto son exactamente lo mismo, es decir, denotan exactamente lo mismo, hay identidad óntica entre ellos sin reserva alguna. La diferencia entre los dos conceptos, alma e intelecto, radica en la connotación. Denotan al hombre, connota la vida, el alma o el espíritu, tres tipos de funciones vitales del hombre. «Intelecto» o «inteligencia» connota la función cognoscitiva, exactamente actividad vital natural y una del mismo hombre, espíritu, alma o vida intelectiva que denota el término.

\section{LA ACCIÓN FUNCIONAL, DIFERENCIADORA DE DENOTACIÓN Y CONNOTACIÓN EN EL INTELECTO}

Pero, en tanto que ejerce el espíritu su función connotada por «intelecto» —entender, conocer de alguna de las maneras posible-, siendo el mismo espíritu, el tal intelecto no es libre, sino sujeto a la realidad: ha nacido esta actividad para presencializar la realidad tal como es, no para perderse en lo posible, lo futurible, lo apetecible. En tanto que «espíritu», por lo contrario, ejerce sus funciones en ser libre y sólo puede por naturaleza ser libre y dueño de sí, perfectamente autónomo y creador responsable y único de su plenitud o de su destrucción, incluso noética. Es la función denotada por los diversos nombres lo que puede llegar a ser contradictorio sin que ello origine la más mínima fisura en la unidad del sujeto. Importa sumamente distinguir funciones, porque es fundamental no triturar al sujeto óntico en facultades «reales», en piezas que estropean su unidad substantiva vital de proto ousia.

Ockham tiene perfectamente clara la posibilidad y normalidad de poseer sobre una única entidad varias «definiciones esenciales», incluso contradictorias. Tan clara posibilidad es esta posibilidad como es clara la imposibilidad de conocer una «esencia substancial» única y última, definitoria del ser en sí de una cosa. La diferencia de esencias de una sola entidad - versión ampliada de la multiplicidad franciscana de formas en un único sujeto- se inscribe en un nivel de discurso diferentísimo del monoformalismo o monoesencialismo. No puede darse en una Physis consecuente, requiere consciencia subjetiva y reflexión epistemológica en alto grado desarrollada. Por esto los «físicos» por excelencia de la antigüedad - los estoicos- exigían infalibilidad, impecaminosidad y ataraxía absoluta a su «sabio», por mucho que los antiguos más conscientes buscaran compaginar discursos contradictorios de los «sabios» y aún renunciar al ideal de sabio, como se expone en la Apología de Sócrates de Platón.

La pluralidad de esencia y definiciones esenciales se coloca sobre la línea de la diversificación de funciones, en una cosmovisión eminentemente dominada por la actividad humana. El monoformalismo y monoesencialismo, por lo contrario, se inscribe primero - y con muchos matices en Platón, Aristóteles y Epicuro- en una cosmovisión monista y fisiológica; luego, ya en la Edad Media, surge en una taxonomía de un mundo en el que tienen todavía predominio los valores de la Physis sive Natura. 
Con Ockham ya comienza a existir la posibilidad de que la esencia sea causada por una proposición protocolaria primera que genera una determinada ciencia específica, dentro de una «naturaleza» que ya refiere más a unas reglas regulares de utilidad o de transformación de lo ya dado en un proceso productivo - ciencia como reglas operativas, y nada más, de la técnociencia-, que a algo que dé la explicación genética-causal de la entidad substancial, dada en, por y para el todo cósmico.

\section{UN PARALELISMO TEOLÓGICO E IMPLICACIÓN EN LA MODERNIDAD}

En el caso del Dios Trino, la acción ad extra de la creación se atribuye a las tres Persona como un todo, por mucho que se pueda señalar rasgos -incluso predominantes - correspondientes a cada una de Ellas. En Ockham, buen teólogo al fin, la persona inteligente realiza siempre como un único todo simple, las funciones más diversas, pese a que cada una sirva para atribuirle un nombre connotativo diferente y las funciones presenten incluso características opuestas.

El tema del intelecto es un caso especialmente claro de connotación de unas funciones que alcanzan a ser contradictorias sin implicar pluralidad de realidades originarias denotadas. Y la característica principal, «espíritu» libre a ultranza incluso en su acción cognoscitiva con «intelecto» totalmente sometido a la «realidad», señala claramente la adscripción de Ockham a la problemática de la Modernidad: dignidad e inviolabilidad del individuo humano, necesidad y certeza absoluta de las ciencias. En el fondo, la clara oposición y dualidad de sujeto y objeto que subrayará tantísimo Kant y que caracteriza historiográficamente el periodo de Modernidad, frente a Antiguiedad o post-Modernidad.

Ver cómo Ockham consigue compaginar libertad, incluso noética, y realismo absoluto del conocimiento, requiere estudiar toda la epistemología, a la vez creativa y realista, del franciscano. Son dos verdades, la libertad del espíritu hasta la creación y la necesidad realista del conocimiento, las cuales, en el Inceptor, se armonizan. Pero no, evidentemente, como en los presupuestos y áreas de sus antecesores. Estamos ya ante el Homo modernus, en un grado de desarrollo no alcanzado en el s.XIII.

\section{INTELECTUS AGENS ET PATIENS: OPOSICIÓN INNECESARIA POR UN CAMBIO DE CAUCE EPISTEMOLÓGICO}

Tal vez el lector vaya pensando para su coleto, que para este viaje no era menester tan pesadas alforjas. Tal vez sospechará que, como es bien sabido, la Modernidad —algo prematura en nuestro autor, como flor de almendro anunciando la primavera ya en febrero- se caracteriza por andar perdida por las sendas del lenguaje que, en su frivolidad, se le antojan profundidad abismal y cima excelsa. Quien está acostumbrado a anteriores y substanciosos manjares, el nominalismo se le antoja piruetas de saltinbanqui, propias de quien perdió la realidad y el gusto por la verdad.

Este lector que nos hemos imaginado, dará en pensar que con la lindeza de los signos denotativos o connotativos, Ockham ha reducido el grave problema del conocimiento verdadero a verborrea decepcionante, a palabrería, a soluciones vocales y no reales. Sospechará que Ockham no es un final de etapa e inicio de otra totalmente diferente, sino otra alma de buena voluntad indudable, pero víctima de las alucinaciones del mundo sensible aparente —como dice Anselmo de Canterbury de Roscelinus de Compiege-y de los discursos de pirotécnica retórica.

Algo de verdad hay en eso y, por lo menos, se ha de agradecer al imaginario lector que no aplique medios más expeditivos o violentos, y caritativamente intente salvar buenas volunta- 
des débiles. Algo de verdad hay en que el alma débil no ha sido desviada de la seriedad y la realidad por una compulsiva masa de hechos, ni tan sólo de datos organizables y racionalizables. Ya decía Cicerón que los denostados "nuevos académicos" veían ni más ni menos las mismas nubes, los mismos cielos y el mismo mar que epicúreos, estoicos y peripatéticos, y afirmaban lo que todos afirmaban, aceptaban lo que todos aceptaban, y se dolían de todo lo que dolía a las demás escuelas.

La única diferencia entre los nuevos académicos y los demás era que aquellos nunca dogmatizaban, siempre cautos en no caer en la desmesura - turpitudo, dice el Cónsul- de hacer absoluto lo que sólo era una opinión bien probada negativamente por coherencia. Siempre temerosos de errar, sólo asignaban verosimilitudo a sus afirmaciones, cualidad más que suficiente para dirigir con seguridad la vida propia y la de la comunidad. Raramente el hombre tiene otro criterio: que lo coherente con todo cuanto sabe le ha de llevar al punto al que apunta. Una aprobación por coherencia negativa se parece muchísimo a la falsación formal popperiana y es muy aceptable en el marco de una fenomenología husserliana.

El discursismo realista de Ockham es un paso más en la dirección de la fina epistemología de la Nueva Academia, y fácilmente admitiríamos que en la tradición más auténtica de los grandes clásicos, como señalaba Cicerón. Y, que no era un mal criterio el de Ockham para la producción de objetos y medios de vida, lo demuestra el éxito de las tecnociencias que nacieron en la Modernidad, estrenada a diferente nivel por el substantivismo cosista de Tomás de Aquino y el falso nominalismo del realista Ockham, tan remoto a Tarsky y también del virtualismo semiótico de hoy.

Y aún aventuraríamos que la malicia del saber moderno según sus detractores, no es precisamente el uso del nominalismo que le achacan, sino la recaída y la recuperación del monotonalismo dogmático estoico por parte de los falsos científicos y la ideología cientifista. El mundo virtual del conocimiento de hoy es la, por ahora, última versión de la tradición epistemológica, la más antigua y la más fecundamente joven, del «nadie es sabio sino Apolo».

Se trata de una tradición que cada vez economiza más y más implicaciones ónticas, sin por ello perder ni un ápice de fuerza. Una tradición que cada vez refuerza más la estupenda creatividad de la inteligencia finita, sin confundir la razón con la utilidad, la argumentación con la eterna realidad, la proposición protocolaria primera con la tautología formal. Que puede «interleerlo» (etimológicamente: inter-legere) todo y, en todo caso, «com-prenderlo» (com-praendere) en la historia, según el sensato aforisma jurídico: distingue tempora et concordavis iura o el más sensato y potente intento de «concordia» verdaderamente histórica del Nuevo y el Vetero Testamento - dos iura- de Joaquín de Fiore.

\section{INTELLECTUS EST SUBSTANTIA ANIMAE POTENS INTELLIGERE}

«Intellectus est substantia animae potens intelligere» (Ockham: II Sent., q. 24) es la toma de posición diáfana de Ockham. En segunda instancia, a título de inclusión en el entramado total de su epistemología, Ockham explica:

«Intellectus agens et possibilis sunt omnino idem re et ratione; tamen ista nomina vel conceptus bene connotant diversa, quia intellectus agens significat animam connotando intellectionem procedentem ab anima active, possibilis autem significat eamdem animam connotando intellectionem receptam in anima, sed idem omnino est efficiens et recipiens intellectionem.» (Ockham: II Sent., q. 24, subrayamos nosotros)

Y aún explicita en una reflexión aparentemente ontológica, porque lo sería efectivamente en otros autores contemporáneos: 
«Actus intellectus agentis est tantum causare intellectionem... et nullam aliam actionem habet circa fantasmata, sicut alii imaginantur, quia nec depurationem nec illuminationem.» (Ockham: II Sent., q. 24; Cf. 9. 16)

Se trata simplemente, no de ontología, sino del querer vivenciar un contacto inmediato del espíritu libre con la realidad en sí de un átomo de realidad, para construir un fidedigno discurso sobre ella. No abstrae, purifica, extrae..., simplemente quiere palpar así, aquí, y ahora el "esto" que busca en vistas a decirse lingüísticamente —operación sucesiva compleja, como levantar un plano- dónde y ante qué está el espíritu en este momento. Y nótese que aquí no hay manipulación, retoque o condicionamiento de la vivencia intelectual por parte del espíritu, alma o vida: los ajustes y relaciones no se dan hasta la formulación, absolutamente inmanente, de la proposición y su aceptación en un juicio lógico-epistemológico, un doble acto de la proposición más simple (cfr. el mismísimo inicio del ya citado texto de I Sent., Prologus, q. $1^{\text {a }}$, a. 1)

El discurso de Ockham sobre el intelecto y los dos intelectos es fiel a la mejor tradición aristotélica. Para el Estagirita la sub-stantia (lo que está debajo, permanente, ousía y hipóstasis), siempre es incognoscible directamente, en sí misma, y sólo caracterizable por sus accidentes. La estimación de "cosa directamente patente" de la substancia no fue nunca griega clásica, como no lo fue la exclusividad absoluta, cerrada y férrea definición esencial posterior. Precisamente por eso Platón y Aristóteles hacen causa común contra las heredadas «ideas» eternas y substantivas de los neopitagóricos en retroceso desde a la mera aritmeticología del número como estructura del Cosmos: son en exceso excluyentes, hasta imposibilitar su función de paradigmas ideales de comprensión.

Esta patencia directa de las substancias - una substancia o entidad y dos funciones-es una simplificación y un primitivismo que luego busca ampararse multiplicando las entidades sin necesidad: substancia, más propios (actos), más facultades, más actos de las facultades, mas accidentes de accidentes. El principio de economía, que no es invento del Inceptor, sino exactamente de aquel que mejor parece, a ciertos ojos, justificar su empleo contra sus natura comunes cum fundamento in re, Johanes Duns Scotus, venía a tajar tal barroca proliferación de «realidades».

Inicialmente Duns Escoto, clara y diafanamente Ockham, ambos optan por el simple discurso mental como epifanía del ente en la subjetividad limitada, finita. Y si sólo el discurso pura y exclusivamente linguiístico - es la realidad en la mente a) se salva la tradicional incognoscibilidad de la substancia en sí; b) se repite para el conocimiento de los objetos lo que ya es verdad adquirida para la subjetividad, tanto divina como humana, es decir, para la substancia inteligente y la subjetividad; c) se respeta absolutamente la inviolabilidad del ente como unidad, ens et unum convertuntur; d) se acepta la tradición platónico-aristotélica sobre cuál es el problema de la mente humana: que necesariamente necesita varios discursos, incluso contradictorios, para conocer la realidad y seguir sus procesos, pero luego ha de superar las contradicciones y las multiplicidades sensibles en un movimiento intelectual dialéctico.

\section{LAS DIFERENCIAS FRENTE A LA TRADICIÓN AMADA, PERO SEGUIDA INTELIGENTEMENTE}

Una cosa bien clara separa y matiza la continuidad entre la tradición clásica y la versión escoto-ockhamista: para los últimos la inteligencia humana noéticamente está sola, aislada en su finitud. No hay un nous cósmico a participar, no hay verdad alguna que surja en la mente por iluminación agustiniana. El nous cósmico implicaría monismo panteísta; la iluminación divina trabaja a niveles no psicológicos, no perceptibles, y no puede ser tomada en referencia para el caso.

Como consecuencia, el lenguaje sensible, la escritura y el habla, que tan a trasmano aparecían en la epistemología de Platón, Aristóteles y aún Agustín, como instancia incordiante, sal- 
tan al mismo nivel de dignidad del discurso mental, interior. Pero reconocer su nueva dignidad al lenguaje sensible - mal que sea muy limitada en Ockham-, ya le obliga a trabajar en un universo absolutamente diferente, el delimitado por el Eriúgena para Dios. Definir el conocer como discurso exige subjetividad sin paliativos.

Dios es absoluto sin duda alguna para el sabio irlandés del s. IX. Incluso demasiado, a juicio de quienes le condenaron en París en la honrosa compañía de Aristóteles en 1210. Pero, si de hecho Dios creó lo otro de sí en un mundo de pluralidad y sucesión, para desvelar su ser riquísimo creandose al crear, luego tuvo que recogerlo en Sí con la radical negación que constituye la cuarta specie. El Dios eriugeniano, es y no es el todo cósmico, por algo más de lo que impide al arché aristotélico ser expresivamente su propia plenitud en la Physis, pese a ser in nuce toda la Physis a la vez. Cuando Ockham reduce el conocer de la subjetividad limitada a discurso, como en el Eriúgena a discurso inmanente creador, ha de explicitar que la acción de conocer es ternaria, dialéctica.

Conocer en Ockham es efectivamente cuestión de tres: la substancia intelectual, el discurso y la realidad objetiva. Pero en su mundo Ockham no posee aún la verdadera herramienta para la subjetividad humana. Como el Kant de la Kritic der Reiner Vernunf, quedará prendido en la dualidad irreductible para él de reglas formales y dados empíricos que generan el objeto en un discurso inmanente al yo trascendental.

\section{OCKHAM Y LA CONNOTACIÓN: NO ES UNA SOLUCIÓN MERAMENTE VERBAL}

Lo que Ockham ha hecho no ha sido dar una mera palabrería doctrinaria con su «connotación» frente al rechazo de los intelectos. Ha recuperado una dimensión y se ha negado a hipostatizar una hipótesis. Ha recuperado el discurso real y mental como problema de la inteligencia, y se ha negado a modelizar en un discurso categorial - ni aún como hipótesis epistemológica en una «teoría del conocimiento»- el yo substancial, el alma inteligente creadora de discursos y síntesis de discursos. Y, en esto no ha quedado corto, sino que ha sido fiel a la tradición, como lo serán Spinoza, Leibniz y el Kant maduro, que darán la mediación moderna para la posmodernidad de Hegel.

A Ockham le faltan - no existe en su entorno- la verdadera noción de historia y la actual abstracción hipotética de una epistemología semiótica, que unifica discursos sin interferir en ellos, sino conservando toda su virtualidad de discurso. Falto de tales instrumentos, herramientas de trabajo del filósofo y no simples opciones hermenéuticas, ha de quedar en la tenue y germinal subjetividad inteligente, negativa como buena substancia -equiparable al nous divisor del uno continuo more geométrico aristotélico- y la brutal y no reducta dualidad lingüística de gramática y dato empírico (intuición intelectual o sensible). Y su propio trabajo discursivo ya empieza a tener cierto tufillo larvado de formalismo al limitarse a un concepto lingüístico de discurso.

Ockham es capaz de reconocer y calibrar muy bien:

«Intellectus multipliciter accipitur, aliquando pro potentia anima e quae non differt $a b$ anima... aliquando pro habitu principiorum, et sic accipitur in libro Posteriorum et VI Ethicorum; aliquando pro intellectione... Praeter praedictos modos intellectus potest aliter accipi secundum diversas opiniones. Nam secundum unam opinionem... potest... accipi pro entibus rationis quae nullum habent esse, nisi objectivum... Sed secundum aliam... potest etiam intellectus pro a li $q$ u o formato in intellectu accipi.» (Ockham: I Sent. Prologus. q. 8. y Expositio Aurea, fol. $91 \mathrm{~b}$ c. Subrayamos nosotros)

O bien: 
«Haec propositio... potest habere duplicem intellectum.» [= Significado, sentido, denotación] (Ockham: Quodl. III, q. 12)

Todo esto cae perfectamente dentro de la ciencia filológica semántica o en la de la ciencia lógica formal. Lo que Ockham, junto con Aristóteles, siempre busca y siempre menciona como objetivo de su trabajo, es valorar cuánto pone la inteligencia - la creatividad del alma o vida inteligente - y cuánto halla intuitivamente y dónde salta la verdad o la falsedad, la posibilidad o la imposibilidad. Cuánto es relación y cuánto es ente intuido, completo, concreto, suficiente y real. Por esto la continuación del Inceptor más abarcante, pero en la misma dirección, será la analítica trascendental kantiana y a la vez el empirismo de lo dado humeano. Es la forma y el contenido real del discurso lo que los tres buscan y hallan.

Lamentablemente los tres olvidan, marginan sin negarlo, al sujeto real del discurrir activo y creador. Lo tenía en Dios el Eriúgena - su cuarta species meramente negativa-; lo menciona Ockham y lo mantiene activo en tódos sus tratados, pero lo pierde al confundir teología negativa con negación formal. Ockham no aprovecha, quizás porque indirectamente ya le llega estropeada la teología negativa no formal de los «hyper-» (Periphyseón), que permite en el Eriúgena razonar lo que Ockham hace pero no dice, y en consecuencia hace que se convierta en pura ausencia en los científicos menores que le suceden, y ellos reifican, absolutizan y exclusivizan el discurso, sin ablandarlo con el sujeto que dice para algo muy determinado y no en un pobre tercer mundo abstracto.

\section{SUJETO Y OBJETO EN EL DISCURSO DE GUILLERMO DE OCKHAM}

Propiamente Ockham lo hace y lo dice, tiene muy presente la subjetividad, pero sólo per transendam, sin verdaderamente usarla. Por ejemplo, con gran claridad proclama:

«Quod est sic intelligendum, quod talia, cuismodi sunt motus et mutatio et huiusmodi [espacio, tiempo,..., intelección, argumentación!], quae important succesionem, nondum habent esse completum, hoc est, I) non sunt entia completa secundum se tota distincta a rebus permanentibus, 2) nec sunt quaedam completa secundum se tota [positiva] composita realiter ex rebus permanentibus; sed 3) esse eorum componitur ex actionibus animae in eo, quod est non-ens extra animam, hoc est, aliqua importata per talia non habent esse extra animam, quamvis posint cognosci ab anima, et aliquid importatum ab eis est extra animam.» (De Successivis, III, Ed. Ph Böhner, p. 97 = Exp. l. Phys. IV, c. 18)

Propiamente el texto describe la vida cognoscitiva inteligente, un dinamismo automotor que se dice en un proceso y obra en consecuencia dentro de este proceso. Hay consciencia de «decir-decirse como un yo en un mundo», por expresarlo anacrónicamente. Pero de la terna yo, decir, mundo- el primer término es relativo y negativo, como quería el Eriúgena y volverá a recuperar Husserl. Y como relativo y negativo, el yo caer frente a la positividad de discurso y mundo. En verdad Ockham lo valoraba al revés al tratar del conocimiento como texto, pero la semiótica, vaciadora de positividades discursivas, no le es asequible a Ockham con suficiente consciencia de ella. Y la "substantividad del yo" le parece sólo concomitante del arte del discurso positivo sobre el mundo que en el discurso se descubre y también es sólidamente concomitante, pero manipulable con urgencia constringente, coartiva y coactiva en la necesidad de subvenir necesidades o evitar errores y peligros. Como no está usada la subjetividad es como debiera ser: el "todo" constructor absoluto del discurso, porque este no refleja la realidad, sino que dice lo real únicamente como signos arbitrarios pero eficaces.

Así viene a quedar ociosa su estimación: 
«Actus intellectus agentis est tantum causare intellectionem... et nullam aliam actionem habet circa fantasmata, sicut alii imaginantur, quia nec depurationem nec illuminationem.» (Ockham: II Sent.., q. 24 Cf. 9. 16)

El inteligir del nous cósmico aristotélico era una acción vital, un acto pragmático y práctico de la vida inteligente. El de la substancia inteligente humana de Ockham debiera haberlo sido tanto por el texto anterior como por el rechazo de las divisiones ociosa anti-económicas:

«Idem intellectus numero est practicus et speculativus... tamen isti termini distinguuntur et habent distinctas definitiones exprimentes quid nominis eorum... Intellectus speculativus est intellectus potens considerare illa quae non sunt in potestare nostra... Intellectus practicus est intellectus potens considerare vel habere scientiam illorum quae sunt in potestate nostra.» (Ockham: I Sent., Prol. q. 10, Cf. q. 12)

El mismo intelecto es especulativo y práctico, considera lo formal y lo metalinguístico, lo posible y lo posible pero irreal o meramente futurible. Pero nunca el único intelecto intelige sin que sea acto de decirse a sí mismo en el mundo. Siempre es un discurso pragmático, simplemente porque es vida. Pero, Ockham, que lo reconoce, luego lo olvida en favor de la mayor urgencia de la práctica de los discursos concretos bien acotados. Le acucian los problemas de la definición de ciencia objetiva, tan espléndidamente acotada en el Proemio a la Expositio libri Physicorum Aristotelis. Le urge la mentalidad universitaria, las polémicas de una época tan renovadora, las luchas finalmente entre Imperio y Papado que, tan de lleno, acaban arrastrandolo junto con sus superiores de la Orden Franciscana.

Ockham, como todos los grandes pensadores, es un Venerabilis Inceptor, acorde con la época que les toco vivir, no un vademecum ucrónico de fórmulas eternas.

F. J. Fortuny

Departamento de Filosofía

Facultat de Filosofía

Baldiri Reixac, s/n

08028 Barcelona 